\title{
Energy Resources and Potential GNP
}

\author{
ROBERT H. RASCHE and JOHN A. TATOM
}

\begin{abstract}
$T_{\mathrm{H}}$ HE dramatic change in supply conditions for energy resources since 1973 had a substantial effect on the productive capabilities of the U.S. economy. Higher prices of energy resources, relative to the prices of labor and capital resources, resulted in a loss of economic capacity and higher output prices. It has been estimated that four to five percentage points of both the higher price level and reduction in national output in 1974 were due to the increased scarcity of energy resources entailed by the quadrupling of OPEC petroleum prices. ${ }^{1}$
\end{abstract}

The loss of national output because of energy market developments was a permanent loss. The energy price revision reduced the effective supply of resources available. Thus, the rate of output achievable by fully utilizing the nation's resources, the "potential" output of the economy, was lowered.

Conventional methods of measuring the economy's potential have focused primarily upon the availability and productivity of labor resources. More recently such efforts have also attempted to account for the availability and productivity of capital resources. Estimates of potential output which consider the relationship of only capital and labor resources to national output are not well suited to the task of accounting for the effects of changes in the availability or cost of energy resources. Nevertheless, the Council of Economic Advisers (CEA) has recently pointed to evidence which indicates that a permanent drop in the productivity of U.S. capital and labor resources may have occurred after 1973. The CEA suggests that this drop is due to the higher cost of energy resources. ${ }^{2}$

A direct route to estimating potential output, which accounts for the supplies of labor, capital, and energy resources under conditions of full utilization, is possible. Such an approach shows that a preoccupation with the supply of energy resources in measuring potential output is not important prior to 1973. Only

1See Robert H. Rasche and John A. Tatom, "The Effects of the New Energy Regime on Economic Capacity, Production, and Prices," this Review (May 1977), pp. 2-12.

${ }^{2}$ See Council of Economic Advisers, Economic Report of the President, 1977, pp. 55-56. small year-to-year changes in the relative scarcity of energy occurred before 1973. The effect of such changes was minor and capable of being captured by the trend growth of productivity of labor and capital. However, such a direct approach also demonstrates the fundamental importance of accounting for energy in measuring potential output after 1973. When energy is included in the production relationship linking resources to output, the effect of the increased scarcity of energy is seen to be of the magnitude of our earlier estimates which were based upon economic theory and more indirect evidence.

Aside from clarifying the recent performance of the U.S. economy relative to its potential, estimates of potential output which account for energy resources have important implications for economic and social prospects. Potential output measures which do not include the loss due to the change in the world energy market overstate the gains in output achievable by full utilization of resources. Consequently, such measures, in addition to endorsing impossible short-term growth possibilities, foster an inflationary bias in efforts to achieve an unattainable potential output. Also, unrealistically high estimates of potential output imply corresponding overestimates of the tax revenues associated with full resource utilization. Thus, federal budget planning tends to have a greater bias toward deficits.

\section{THE DEVELOPMENT OF MEASURES OF POTENTIAL GNP}

\section{The Original CEA Estimates}

The notion of potential GNP, the output rate produced when the economy fully utilizes its resources, was first developed by the Council of Economic Advisers in 1962.3 The original estimates of potential GNP were based on three simple statistical approaches

3 See Council of Economic Advisers, Economic Report of the President, 1962, pp. 49-56, and Arthur M. Okun, "Potential GNP: Its Measurement and Significance," American Statistical Association, 1962 Proceedings of the Economic Statistics Section, pp. 98-104, also reprinted in his The Political Economy of Prosperity, (Washington, D.C.; Brookings Institution, 1970 ). 


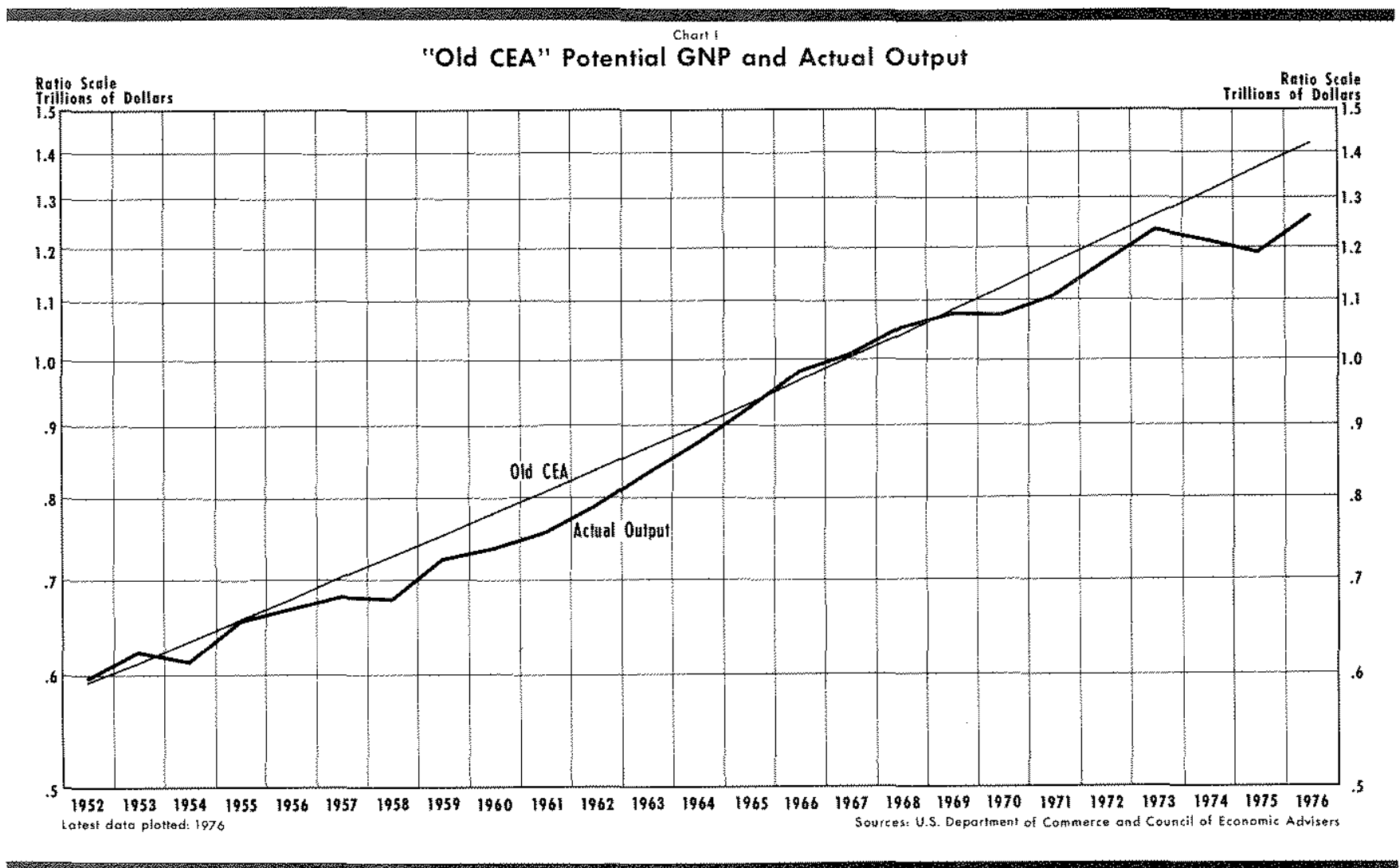

developed by Okun that related the unemployment rate to actual real GNP. The estimates assumed that full utilization of resources occurs when the unemployment rate for the civilian labor force is four percent, that is, the economy operated at its potential in mid1955. The original estimates assumed that potential output grew at an annual trend rate of about 4.5 percent from 1947 to 1953 , and at about a 3.5 percent rate from 1953 to $1962 .{ }^{4}$

The original estimates achieved widespread recog. nition. The simple device of relating departures of the unemployment rate from four percent to the "gap" between actual and potential output facilitated the popular discussion of both economic goals, such as full employment and growth, and fiscal policy. With regard to the latter, the notion of a high-employment Federal budget was developed and used to indicate the state of the budget deficit or surplus under high-employment economic conditions as well as the magnitude of fiscal efforts required to move the economy to a four percent unemployment rate.

Since these original estimates, the CEA has recognized that various forces, particularly demographic

4See Okun, "Potential GNP," pp. 101-02. factors, can change the trend rate of growth of resources and, hence, potential output. Consequently, the CEA has from time to time adjusted the trend rate of growth used to update their data series for potential output. From 1952 through 1962, the CEA uses the 3.5 percent trend rate of growth derived by Okun. This trend rate was raised to 3.75 percent for the period from 1962 through 1968 and further increased to four percent from 1969 through 1975 . Because of a slowdown in the rate of growth of the labor force, the CEA reduced the trend rate of growth of potential GNP after 1975 to 3.75 percent. This series is referred to below as the "old" CEA estimate and is shown in Chart I along with actual GNP. ${ }^{5}$

Okun indicated in his original work that his analysis skipped over important links between changes in the unemployment rate and output, and in an often quoted passage he concluded:

Still, I shall feel much more satisfied with the estimation of potential output when our data and our analysis have advanced to the point where the esti*

5 For a full description of the old estimate see the note in U.S. Department of Commerce, Bureau of Economic Analysis, Business Conditions Digest (September 1976), p. 95 and the discussion in issues of the CEA Economic Repott since 1962. 
mation can proceed step-by-step and where the capital factor can be taken explicitly into account ${ }^{6}$

Since 1962 several studies have attempted to improve upon the original work. The major efforts attempted to account for capital resources and for the interaction between actual output and prospective potential output. The major development has been to use an apm proach based upon an aggregate production function. ${ }^{7}$ However, until recently no serious problems have been detected with the old CEA estimates. ${ }^{8}$

\section{The "New" CEA Potential Output Series}

More recently, studies of potential output have indicated some major departures from old estimates. In addition to the slowdown in the long-term growth of the labor force pointed out by the CEA in the fall 1976 revision of the growth trend, a study by Data Resources, Inc., suggests a further slowdown since 1973 because of a substantial decline in the growth of the capital stock. ${ }^{9}$ More importantly, the CEA itself has pointed out an apparent slowdown in productivity growth since 1966. Clark has developed a new potential output series for the CEA which is based, to an extent, on production function estimates rather than simple trends. ${ }^{10}$ These new estimates imply a growth rate of potential output of about 3.5 percent in the

Gokun, "Potential GNP," p, 104.

${ }^{\top} \mathrm{A}$ few of the major studies are: Edwin Kuh, "Measurement of Potential Output," American Economic Review (September 1966), pp. 758-76; Lester C. Thurow and L. D. Taylor, "The Interaction Between the Actual and the Potential Rates of Growth" The Review of Economics and Statistics (November 1966), pp. 351-60; Stanley W. Black and R. Robert Russell, "An Alternative Estimate of Potential GNP," The Review of Economics and Statistics (February 1969), pp. 70-76; and Benjamin M. Friedman and Michael L. Wachter, "Unemployment: Okmin's Law, Labor Force, and Productivity," The Review of Economics and Statistics (May 1974), pp. $167-76$.

8For example, see the discussion by George M. vonFurstenberg, "Comments on Estimating Potential Output for the U.S. Economy in a Model Framework," Achieving the Goals of the Employment Act of 1946 - Thirtieth Anniversary Review U.S. Congress, Joint Economic Cornmittee, 94th Cong. 2nd sess., December 3, 1976, pp. 26-28. He points out that more elaborate "supply-oriented models" are valuable for improving understanding but estimates from them are not "demonstrably more reliable" than the old official estimates. He also notes that the usefulness of the old CEA potential output estimates "would be unaffected by anyone showing, for instance, that potential is consistently one percent larger or smaller than officially estimated" (p. 28).

"See Roger Brinner, "Potential Growth to 1980," Otto Eckstein et. al. Economic Issues and Parameters of the Next 4 Years, (Lexington, Massachusetts: Data Resources, Inc., Economic Study Series, 1977), pp. 9-17.

10See the CEA, Economic Report, 1977, pp. 45-57 and Peter K. Clark, "A New Estimate of Potential GNP," Council of Economic Advisers, umpublished memorandum, January 27, 1977. late $1960 \mathrm{~s}$ and early 1970s. These new estimates are in agreement with projections made in 1972 by William Nordhaus. ${ }^{11}$

In two respects the new CEA series on potential output represents a major departure from the methods used to compute the old series. First, potential output now is viewed more as high-employment output rather than being linked to a four percent unemployment rate. The new CEA estimates are based on explicit considerations of participation rates and differential high-employment unemployment experiences of different age-sex groups. The high-employment benchmark of a four percent civilian labor force unemployment rate in mid-1955 is preserved, but the new series is based on explicit estimates of the revision in the high-employment benchmark over time due primarily to changes in the composition of the labor force. The second major departure is an attempt to account more explicitly for capital resources in the estimation of productivity and potential output. However, the new estimates of the CEA do not take into account a further one-time reduction in productivity and potential output which their analysis indicates occurred in 1974 and which they suggest may be a permanent change due to the energy price shock. ${ }^{12}$

A comparison of the new and old series is presented in Chart II for the period 1952-1976. Until 1967, the two CEA potential output series are very similar. The new CEA estimates show potential output to be about one percent lower from 1952 to 1967 , but growing at roughly the same rate. After 1967 the new estimates fall short of the old series by a growing amount. By 1976 the new estimate of $\$ 1363.6$ billion is only 95.9 percent of the old estimate of $\$ 1421.2$ billion. ${ }^{13}$ The bulk of the $\$ 57.8$ billion reduction is attributed to a slowdown in the growth of labor productivity and an increase in the full-employment unemployment rate.

As noted above, the CEA has suggested that productivity fell further in 1974, so that by 1976 , potential output may be $\$ 30$ billion lower than their own new estimates. These new estimates, like those of Data Resources, Inc, mentioned above, assume a

\footnotetext{
11See William D. Nordhaus, "The Recent Productivity Slowdown," Brookings Papers on Economic Activity (3:1972), pp. $493-545$.

12While the Economic Report discusses the new estimates, neither the old nor new series have been published in the monthly publication of the Bureau of Economic Analysis, Business Conditions Digest, since October 1976.

13See CEA, Economic Report, 1977, p. 55. All potential output measures are in constant (1972) dollars throughout this article.
} 


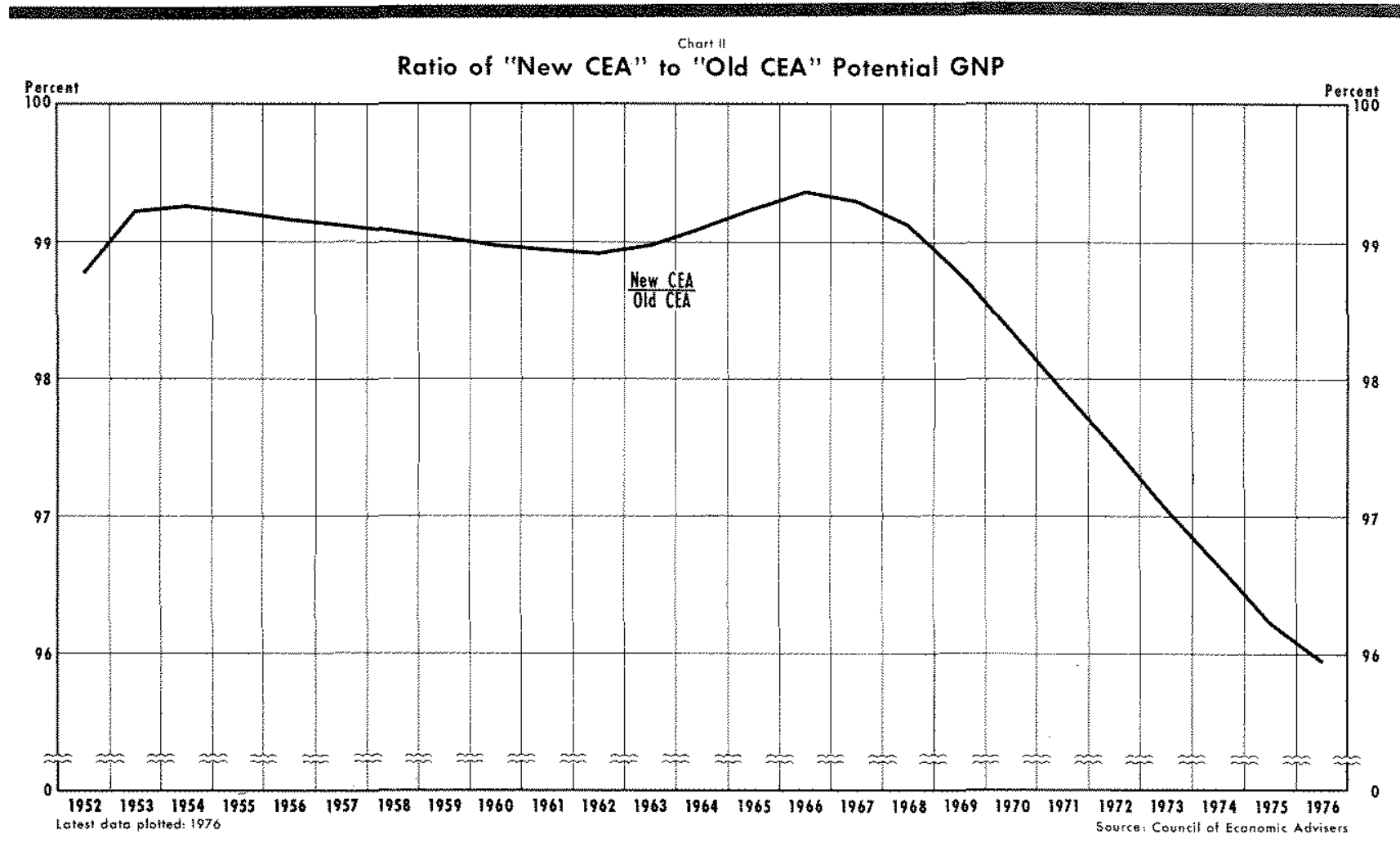

Cobb-Douglas production function with only labor and capital resources and assume output elasticities of one-third for capital and two-thirds for labor. Thus, neither estimate is able to capture fully changes in productivity of labor and capital resources due to reductions in potential energy usage associated with a higher relative price of energy resources.

The production-function approach to the estimation of potential output taken in this article accounts explicitly for energy resources. The potential output measures draw heavily upon the recent work involved in the new CEA measures of potential output, specifically by using their estimates of the potential labor force and the full-employment unemployment rate.

One recent study, that of Eckstein and Heien (E-H), has attempted to account for energy effects on potential output through the aggregate production function. ${ }^{1 *}$ The $\mathrm{E}-\mathrm{H}$ results indicate, however, that in recent years potential output is much higher than the old CEA estimates. While the methodology used in

${ }^{14}$ Albert J. Eckstein and Dale M. Heien, "Estimating Potential Output for the U.S. Economy in a Model Framework," Achieving the Goals of the Employment Act of $1946-$ Thirtieth Anniversary Review, U.S. Congress, Joint Ecor nomic Committee, 94th Cong., 2nd sess., December 3, 1976, pp. 1-25. the E-H study is similar to that used here, the conclusions are markedly different. These differences result from serious data problems and a specification error in their demand for energy. Since their study has such a similar methodology and reaches such different results, a full critique is contained in Appendix $\mathrm{I}^{15}$

\section{ACCOUNTING FOR ENERGY IN AN AGGREGATE PRODUCTION FUNCTION}

The first step in a production-function approach to measuring potential output is the estimation of an

t5̈Another study which includes energy price developments in an estimate of potential output is that by Jacques $R$. Artus, "Measures of Potential Output in Mantufacturing for Eight Industrial Countries, 1955-78, International Monetary Fund Staff Papers (March, 1977), pp. 1-35. Like Clark"s study he finds an energy price impact using a dummy variable approach instead of explicitly incorporating the energy price. Since his study includes seven countries he is forced by data limitations to impose several arbitrary constraints which raise serious questions about the meaningfulness of his coefficient estimates. Relaxing the constraint that the effect is the same across countries, his estimate of the energy price impact is that U.S. potential manufacturing output fell 2.7 percent in 1974 which is below both Clark's estimate of 4.2 percent for the private business sector and our earlier estimate of five percent which is confirmed below. Ignoring the other constraint problems, it may be noted that his estimate is not significantly different from ours given its relatively large standard error. 
aggregate production function. The approach taken here follows the usual practice with one major exception: energy resources are considered as an integral part of the production function. This is in contrast to the usual practice of estimating the functional relationship between output and only labor and capital resources. The latter approach implicitly assumes that changes in the stock and flow of energy resources are captured by movements in the capital stock and need not be explicitly taken into account.

The measure of output for which a production function is estimated is the output of the private business sector. Real GNP includes, in addition to the output of the private business sector, gross output originating in the rest of the world, the output of the general government sector, output imputed to owneroccupied dwellings, and output of households and nonprofit institutions. For estimating potential real GNP these components of actual GNP are simply added to potential real output of the private business sector.

Actual real output in the private business sector depends upon the employment of capital and labor services as well as energy resources. The production function may be written as

$$
\mathrm{Y}=\mathrm{A} \mathrm{e}^{\mathrm{rt}} \mathrm{L}^{\mathrm{\alpha t}} \mathrm{K}^{\beta} \mathrm{E}^{\gamma}
$$

where $Y$ is output, $L$ is labor measured in manhours, $\mathrm{K}$ is the effective flow of capital services, $\mathrm{E}$ is the flow of energy resources, and $t$ is time. The other terms in equation (1) are estimated statistically. The A term is essentially a scaling factor, $r$ is the trend rate of growth of output due to technological change, and $\alpha, \beta, \gamma$ are the output elasticities of the respec. tive inputs. The estimated production function was restricted by requiring that the sum of the exponents $\alpha, \beta, \gamma$ equal unity. The basic implications of such a "Cobb-Douglas" production function are constant returns to scale and partial elasticities of substitution of unity. ${ }^{10}$

The output and manhours data for the private business sector are those prepared by the Bureau of Labor Statistics of the U.S. Department of Labor. The effective services of capital are found by multiplying

\footnotetext{
16Constant returns to scale means that equal proportionate changes in each of the resources employed causes a proportionate change in output. This is a common assumption em. ployed in estimating production functions, especially at such a highly aggregated level. Unit partial elasticities of substitution have also been employed in earlier studies, although alternative production function specifications exist which relax this constraint.
}

the Federal Reserve Board index of capacity utilization times the capital stock in place at the beginning of each period. ${ }^{17}$ The annual capital stock measure is the constant dollar (1972) net stock of fixed nonresidential equipment and structures. ${ }^{18} \mathrm{~A}$ comparable data series on energy use in the private business sector could not be found. However, the rate of energy use in the private business sector is presumably that demanded and the demand for energy is determined completely by the production function and the relative price of energy.

If firms in the private business sector maximize economic profits, they employ energy at a rate where the value of the additional product obtained from employing more energy equals its price. The demand for energy from equation (1) is

$$
\mathrm{E}=\gamma Y\left(\frac{\mathrm{P}_{\mathrm{E}}}{\mathrm{P}_{\mathrm{B}}}\right)^{-1}
$$

where $P_{E}$ is the price of energy and $P_{B}$ is the price of output of the private business sector. ${ }^{19}$ Equation (2) can be used for the energy input in the production function so equation (1) may be found by estimating

$$
\mathrm{Y}=\left(A^{*} e^{\mathrm{yt}} \mathbf{L}^{\alpha} \mathbf{K}^{\beta} \mathbf{P}^{-\gamma}\right)^{\frac{1}{\xi-\gamma}}
$$

where $A^{*}$ is another scaling factor and $P$ is the relative price of energy $\left(\mathrm{P}_{\mathrm{E}} / \mathrm{P}_{\mathrm{B}}\right)$. The relative price of energy is measured by the ratio of the wholesale price index for fuel, related products, and power to the implicit price deflator for the output of the private business sector.

The credibility of the assumed Cobb-Douglas production function is, of course, purely an empirical matter that can be subjected to statistical testing. The assumption implies relatively high price and output elasticities of demand for energy and unit partial elasticities of substitution between energy and capital

${ }^{17}$ In a previous paper, "The Effects of the New Energy Regime," we discussed the possible biases of the FRB capacity utilization index in recent years as a result of changes in the relative price of energy, when it is viewed as a measure of utilization of economic capacity. In the present context, we need a measture of utilized capital. When this index is viewed as such a measure, there is no reason to believe that the change in the relative price of energy has introduced a systematic measurement bias.

185ee John C. Musgrave, "Fixed Nonresidential Business and Residential Capital in the United States, 1925-75," Survey of Current Business (April 1976), pp. 46-52.

19The marginal product of energy from equation (1) is $\gamma \mathrm{Y} / \mathrm{E}$, so the profit-maximizing employment of energy occurs where $P_{\mathrm{E}}=(\gamma \mathbf{Y} / \mathbf{E}) P_{\mathrm{B}}$. 
or labor. ${ }^{20}$ There is, however, some evidence that these properties apply to the U.S. economy. An output elasticity of demand for energy of unity in the long run for at least the United States, Japan, and Western Europe is supported by a number of studies. ${ }^{21}$ Using cross-sectional data and the trans-log production function, Griffin and Gregory have demonstrated that for nine industrial nations the production function has partial elasticities of substitution of energy for capital and labor that are constant and unity, ${ }^{22}$ Most importantly for the purpose at hand, the assumption of a Cobb-Douglas production function cannot be rejected with the data examined.

Recent studies of productivity suggest that in estimating an aggregate production function it is important to account for qualitative changes in manhours and for productivity differences in capital due to the increasing importance of mandated pollution-abatement capital expenditures. ${ }^{23}$ Attempts to control for skill differences by including variables for the composition of the labor force by age were unsuccessful except for the 16-19 age group; a negative effect of the share of the latter group on productivity was not statistically significant when the estimation was adjusted for autoregression. Clark's gross capital stock data are adjusted for pollution-abatement capital. Use of his series produced results essentially identical to those found using the gross nonresidential stock of business capital (constant 1972 dollars). Thus, no attempt is made to adjust the net nonresidential stock of business capital for pollution-abatement capital. ${ }^{24}$

The production function (3) estimated with annual data for the period 1949-75 is given in logarithmic form in Table 1 . The equation was estimated with the constant-returns-to-scale restriction imposed by taking

20The potential biases introduced by assuming a Cobb-Douglas production function and some indications of their absence are discussed in Appendix II.

21 See, for example, Joseph A. Yager and Eleanor B. Steinberg, "Trends in the International Oil Market," Higher Oil Prices and the World Economy: The Adiustment Problem, ed. Edward R. Fried and Charles $\mathrm{L}_{\text {. S }}$ Schultze (Washington, D.C.; Brookings Institution, 1975), pp. 246-47, and the references cited in their footnote 45 .

${ }^{22}$ See James M. Griffin and Paul R. Gregory, "An Intercountry Translog Model of Energy Substitution Responses," The American Economic Review (December 1976), pp. 845 57 .

${ }^{23}$ See, for' example, Clark, "A New Measure of Potential Output."

24 No doubt pollution-abatement capital investment will become an increasingly important factor for such studies in the future. Thus, the problems of measuring such investment will also become more pressing. The unimportance of the adjustment now is due only to its small size to date. For example, in Clark's estimates the pollution-abatement capital stock is only about two percent of the gross fixed nonresidential capital stock by 1975 .

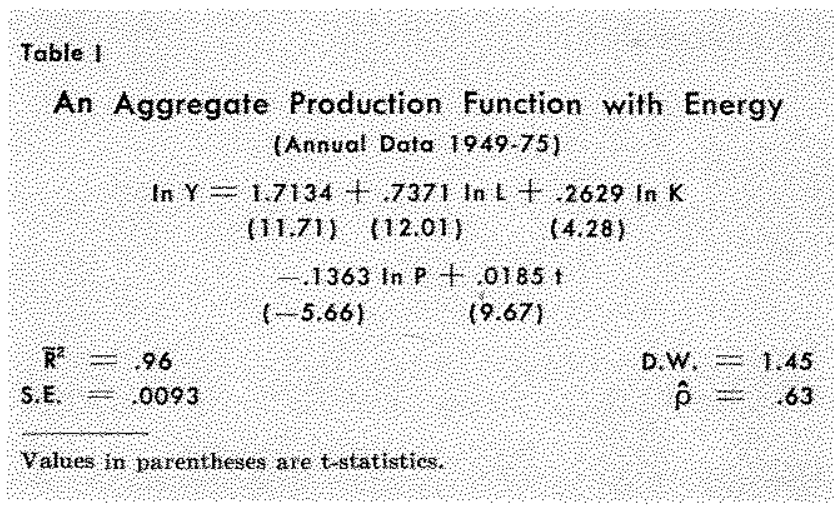

the ratio of output to capital and manhours to capital. The hypothesized negative effect of the relative price of energy is statistically significant.

The estimates of the output elasticities of the production function, based on the equation in Table I, are presented in the Table II. The output elasticity of the energy resource is 12 percent which is consistent with the Griffin and Gregory estimate of the cost share of energy and energy price elasticity of demand for capital. ${ }^{25}$ The latter estimates have been used to show that capacity in manufacturing fell five percent in 1974 due to the 45.3 percent rise in the nominal price of energy from the end of 1973 to the end of 1974. The estimate also supports the assumption that the manufacturing result is representative of the effect of the energy price change on the private business sector ${ }^{26}$ The estimated standard error of the estimate of $\gamma$ is 2.12 percent. ${ }^{2 t}$

The estimate of the output elasticity of labor in Table I is very close to the usual estimate of labor's share of income as well as being approximately equal to labor's average share of cost in the private business sector over the period of estimation. The average share of labor in the private business sector over the sample period is 66.37 percent. A test for the differences between the estimated output elasticity and the sample period average labor share yielded a t-value of 0.2914 . Thus, the hypothesis that the estimated output elasticity of manhours is equal to labor's share cannot be rejected.

Since the relative price of energy changed dramatically in 1974 and 1975, the production function in

\footnotetext{
25see Griffin and Gregory, "An Intercountry Translog Model," pp. $849-52$.

26See Rasche and Tatom, "The New Energy Regime," p. 5 and pp. $10-12$.

27Formulas for computing the variance of the restricted par amaters $(\alpha, \beta, \gamma)$ may be found in Jan Kmenta, Elements of Econometrics, (New York: The Macmillan Company, $1971)$, p. 444 .
} 


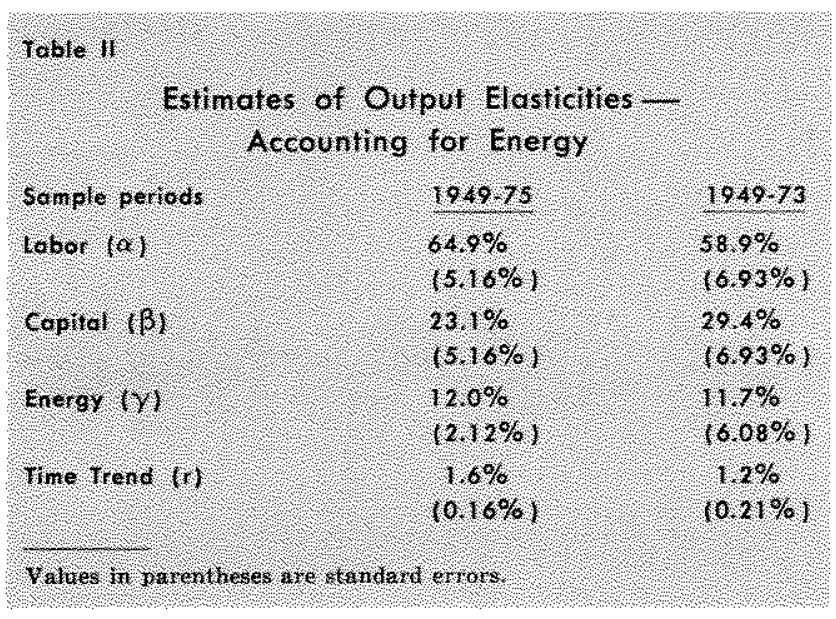

Table I was reestimated over the period ending in 1973 to assess the impact of the large price change on the estimates. The estimates of the output elasticities for the earlier period are also given in Table II. The estimates are practically the same as those for the longer period, especially for energy. ${ }^{28}$ Thus, it does not appear that the importance of energy resources in the production function estimate is due to the dramatic energy developments which have occurred since 1973.

The importance of accounting for energy and its relative price in estimating production relationships is illustrated by the equations in Table III. A standard Cobb-Douglas production function omitting energy is estimated for the two periods 1949-73 and 1949-75. The first equation, for the period prior to the large rise in the relative price of energy, performs about the same as the equation in Table I which includes energy in the production function. When 1974 and 1975 are included to estimate the second equation, however, the simple production function performs much worse. The standard error of the second equation is more than 50 percent larger than that for the earlier period and almost 50 percent larger than that given in Table I. ${ }^{29}$ The omission of energy from production function studies prior to 1974 would appear to be a

${ }^{28}$ The estimated standard error of $\alpha$ is 6.93 percent, so a 95 percent confidence interval for the restricted estimate of labor's share contains the sample average share of 66.2 percent for 1949-73.

${ }^{29}$ For the sake of comparison it may be noted that the stand ard error of the equation in Table 1 over the shorter period, 1949-73, is 82 percent, about the same as for the first equation in Table III. Also, before the Cochranem Orcut adjustment, the coeffcients of the Table III equations are not as stable. For example, the manhours coefficient drops significantly from 62 percent for the $1949-73$ period to 47 percent for the $1949-75$ period. Such a significant change does not occur in the production function estimates which include energy, nor was there a noticeable change in the labor share data for $1974-75$ in private business sector data.

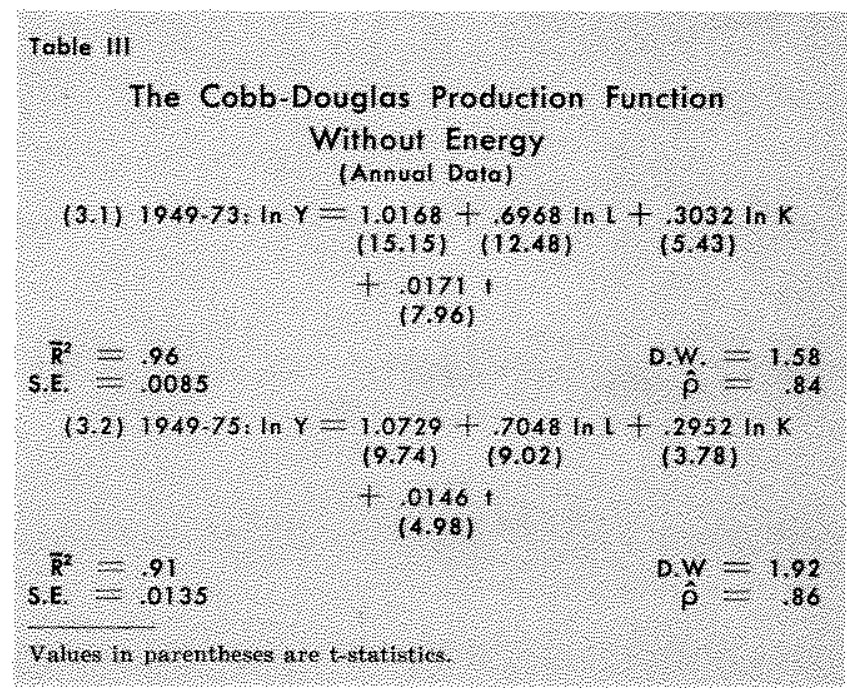

minor problem, if indeed it is a problem at all. ${ }^{30}$ After the dramatic change in energy prices, explicit consideration of energy resources and the relative price of energy resources is required to obtain stable estimates of U.S. production relationships. ${ }^{31}$

\section{AN ESTIMATE OF POTENTIAL OUTPUT}

The production function estimates can be used to estimate potential output in the U.S. economy when supplemented with assumptions concerning the fullemployment availability of resources. The stock of capital available during a period is essentially the same regardless of whether the economy operates at its potential. The utilization rate of capital, however, varies with economic conditions. Consequently, estimations of potential output for the private business sector and the economy as a whole requires some estimate of the utilization rate that would prevail at potential output. Quarterly estimates of the Federal Reserve Board index of capacity utilization in manufacturing since 1948 indicate that the 87.7 percent utilization rate of capital achieved in late 1973 has been exceeded in only two prior peak periods, during the Korean War and the Vietnam War, when it was about 90 percent. During mid-1955, a benchmark year for original studies of potential output,

30The unimportance of accounting for energy in some earlier estimates of the production function is due to its high correlation with time trends and capital. For example, from 1948 through 1970 a trend decline of the relative price of energy of 1.33 percent per year accounts for over 95 percent of its variation with a standard error of two percent.

31 When the energy price is excluded from the production function, a Chow test on the additional observations, 1974-75, indicates structural change at a one percent significance level. At this significance level, equality of the coefficients of the production function including the energy price camnot be rejected when these observations are added. 
the index was 87.5 percent. ${ }^{32}$ This latter rate is used here as the assumed full-employment capital utilization rate.

The flow of manhours at the potential output rate depends upon both the size of the "potential labor force" and the supply of hours per worker at potential output. Clark's recent study provides annual estimates of the potential civilian labor force. The estimates are based upon the population and labor force participation rate of each of eight age-sex groups adjusted for cyclical effects. Clark has also estimated a full-employment unemployment rate annually since 1948 which is equivalent to a four percent unemployment rate in 1955. These estimates are based upon the relationship between the unemployment rate for each of the eight age-sex groups and: 1) the unemployment rate of adult males (age 25-54) and 2) the relative size of the potential group in the potential labor force. ${ }^{33}$ An annual series for potential civilian employment is obtained by adjusting the potential labor force for the full-employment unemployment rate. Potential employment in the private business sector in each period is the difference between potential civilian employment and actual employment outside the private business sector, principally in government.

Hours per worker in the private business sector at potential output is estimated in a fairly standard manner. ${ }^{34}$ Hours per worker varies cyclically as well as secularly. Hours per worker at potential output, adjusted for Clark's full-employment unemployment rate, is estimated using the postwar relationship in Table IV, which treats hours per worker as a function of the unemployment rate and a time trend. Potential manhours is the product of the estimated potential hours per worker and potential employment in the private business sector.

The relative price of energy at potential output is assumed to be the actual relative price. Until 1974 it is conceivable that moving from a smaller output to potential output in any period would have raised this relative price. However, since any change of this type would have probably been quite small given the small variance in this relative price in the postwar period through mid-1973, and since the coefficient of the

32See Richard D. Raddock and Lawrence R. Forest, "New Estimates of Capacity Utilization: Manufacturing and Materials," Federal Reserve Bulletin (November 1976), pp. $892-905$.

33 See Clark, "A New Measure of Potential GNP," pp. 14-22.

${ }^{34}$ For example, see Black and Rissell, "An Altemative Estimate of Potential GNP, $p$ p. 70-76.

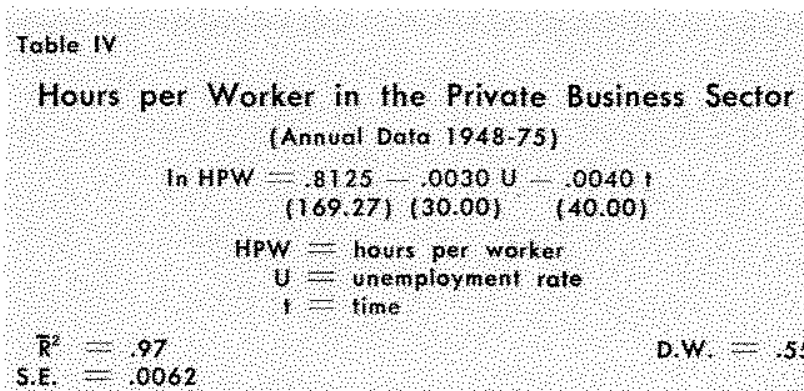

Values in parentheses ate t-statistics

relative price is not large, it is unlikely that the assumption has any noticeable impact on the estimates of potential output.

The production function and the assumptions above provide an estimate of potential output in the private business sector ${ }^{35}$ Potential real GNP is found by adding the actual component of output outside the private business sector. The annual estimates of potential real GNP from 1952 to 1976 are shown in Chart III along with the old CEA series. ${ }^{36}$ Unlike both the new and old estimates of the Council of Economic Advisers, the series is not smoothed. The average annual rate of growth of the series from 1952 to 1975 is 3.4 percent. This is slightly lower than the 3.6 percent average rate of growth in the new CEA series or the 3.7 percent in the old series for the same period.

The estimate of potential output is virtually identical to the old CEA estimates in their benchmark year 1955 as well as in 1969-70. Chart IV shows the ratio of the estimated potential GNP to the old CEA measure of potential output. Except for the early and mid1950s and 1969-70, the old CEA estimates show the economy with greater potential than the estimates here. The chart indicates that the old CEA measure grows more rapidly in the late 1950 s and early 1960 s, but that this is compensated for by a lower estimate of potential output growth in the late 1960s. ${ }^{37}$ Chart

35The exponential of the estimate of the logarithm of potential output is a biased estimate of potential output. An exact correction for this bias is derived in Dan Bradu and Yair Mumdlak, "Estimation in Lognormal Linear Models," Amer" ican Statistical Association Journal (March 1970), pp. 198-

211. The bias correction factor was computed for the estimates of potential output presented here. In no case was the correction more than 1 billion dollars.

36'The equations necessay to construct quarterly potential output employing the same methodology are presented in Appendix III.

3iBlack and Russell, "An Alternative Estimate of Potential GNP," p. 74, also found that the Council overstated the trend growth in the late fifties. The fairly constant percentage from 1963-65 in Chart IV is also in agreement with Black and Russell's claim that the Council estimate of growth was about right in this period. 


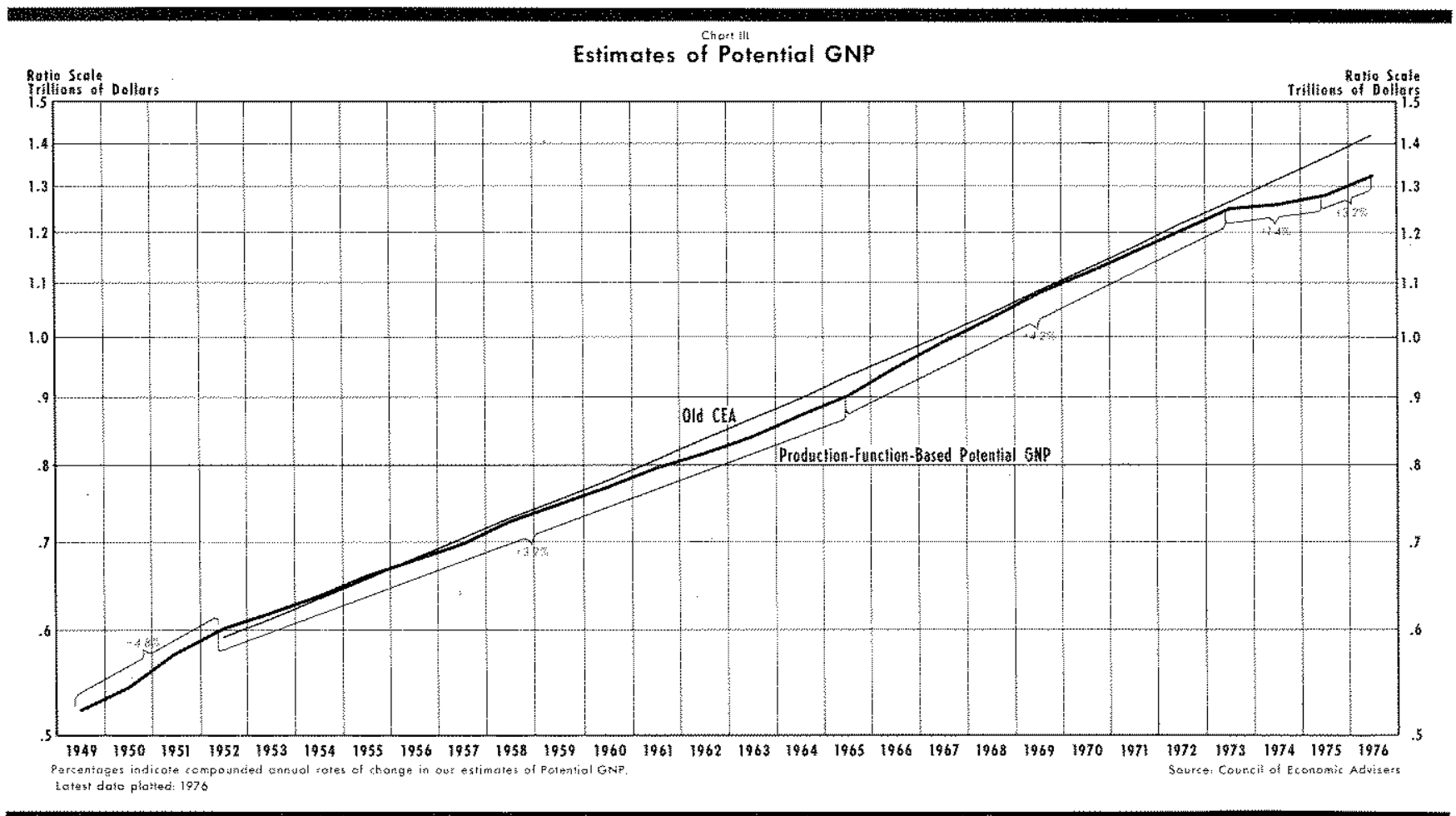

IV also indicates that, according to our estimates, a four percent trend rate of growth is slightly too high for the period 1969.71 and about right for 1971-73.
After 1973, the ratio plummets as the old trend based estimates of potential output are mnaffected by energy developments.

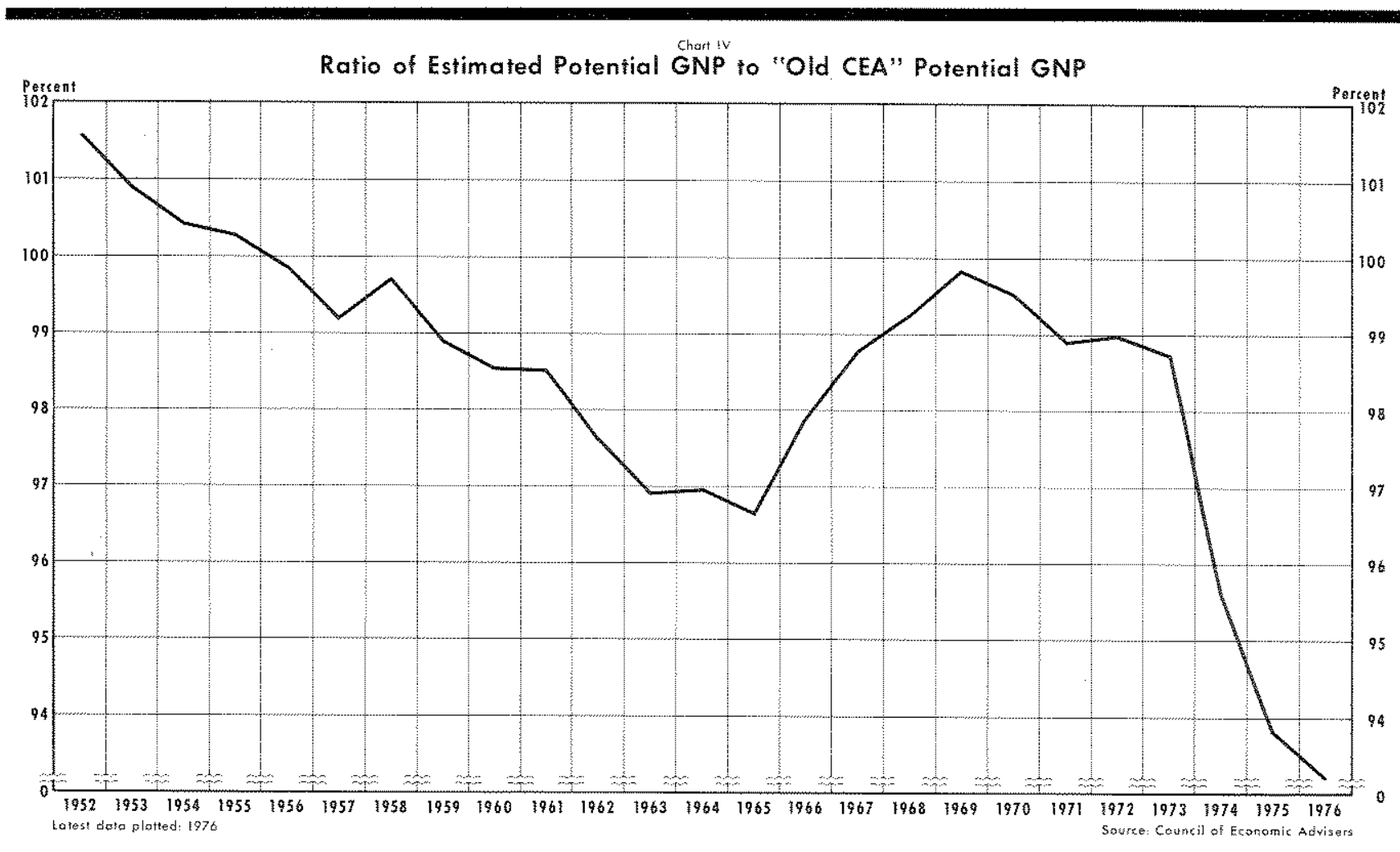

Page 18 
As indicated in Chart II, the new CEA measures of potential output are about 99 percent of the old measures until 1967. Thus, the new CEA series shows potential output to be smaller than the estimates here from 1952-59 and from 1968-73. The new official CEA estimates do not account for energy price developments so they are higher than the production function estimates for 1974-75. However, when the additional productivity shift discussed by the CEA is taken into account, their new estimate of potential ontput for 1974 and 1975 is not much different from those presented in Chart III.

A primary difference, besides excluding energy considerations, between the new CEA potential output series and that presented in Chart III is a produc tivity slowdown in 1967. The new CEA series includes such a slowdown and it is estimated that the trend rate of growth falls 25 percent after 1966 . The timing of this shift appears to be arbitrary and its size appears to be quite large given the reasons cited. ${ }^{28}$ Nonetheless, such a shift is statistically significant when a variable intended to capture such an effect is added to the equation in Table I. Moreover, the size of the reduction in the trend rate of growth agrees with the estimates of the CEA. The estimated equation is presented in Table $V$. It may be noted that the equation implies a significant output elasticity of energy of 9.8 percent and an output elasticity of manhours of 66.8 percent. Given the size of the standard errors of the coefficients, it does not appear that the inclusion of the productivity shift parameter, $\mathrm{T} 2$, significantly affects the results indicated in Tables $I$ and II. The only major differences between the equation in Table $V$ and the equation in Table $I$ are the differences in the trend rate and the slight improvement in the standard error.

For comparison purposes, a potential output series was estimated as before using the production function in Table $\mathrm{V}$. The comparison is essentially the same as that discussed above without the shift term T2. The ratio of the estimated potential output, with and without the slowdown in productivity growth, to new CEA potential output is shown in Chart $V$. The new

\footnotetext{
38The principal source cited by Clark, "A New Estimate of Potential GNP," for the productivity slowdown is the study by I. R. Norsworthy and L. J, Fulco, "Productivity and Costs in the Private Ecoromy, 1973," Monthly Labor Review (June 1974), pp. 3-9. The reason given by Norsworthy and Fulco is a slowdown in the shift of labor from the agriculture sector. The slowdown in the shift appears to be contradicted by more recent evidence. See Robert Reinhold, "Decrease in Farm Population Accelerates: Figures Show at 14 percent Decline from 1970-75," New York Times, April 15, 1977, p. A14.
}

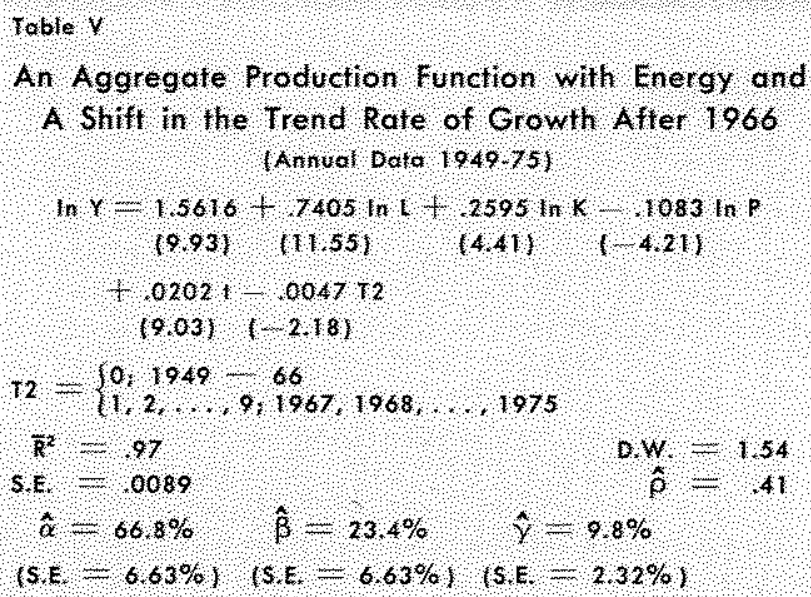

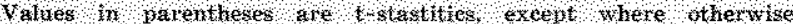
ind icated

CEA estimates are lower than our estimates of potential output before 1959 and in 1968-73. Like the old CEA estimates, the new CEA estimates indicate a higher rate of growth of potential output until the mid-1960s and a lower rate of growth of potential from 1965-69. The new CEA rate of growth of potential output from 1969:73 is in agreement with the energy based estimate. Finally, like the old CEA estimates, the new CEA estimates show a higher rate of growth of potential output in 1974-75.

\section{THE IMPLICATIONS OF NEW ESTIMATES OF POTENTIAL OUTPUT}

Regardless of the historical pattern of the alternative estimates of potential ontput, the new CEA estimates and those presented here have similar implications for the recent and near term performance of the economy. Table VI shows the potential output measures for 1973-76 from the old series, the new series, and those estimated using the equation in Table $I$ and shown in Chart III. ${ }^{39}$ Both of the new estimates show that the economy was much closer to potential output in 1973 than the old CEA series indicates. More importantly, both new series show a substantially slower growth of potential output in recent years, compared to the old series and, thus, a substantially smaller gap between actual and potential output in 1976.

Our estimate of potential output also supports the CEA's recent suggestion that energy price develop-

\footnotetext{
39The conclusions from Table VI would be unaffected by using the production function in Table $V$ since the potential meas* ures for 1973-76 are essentially the same or either basis.
} 


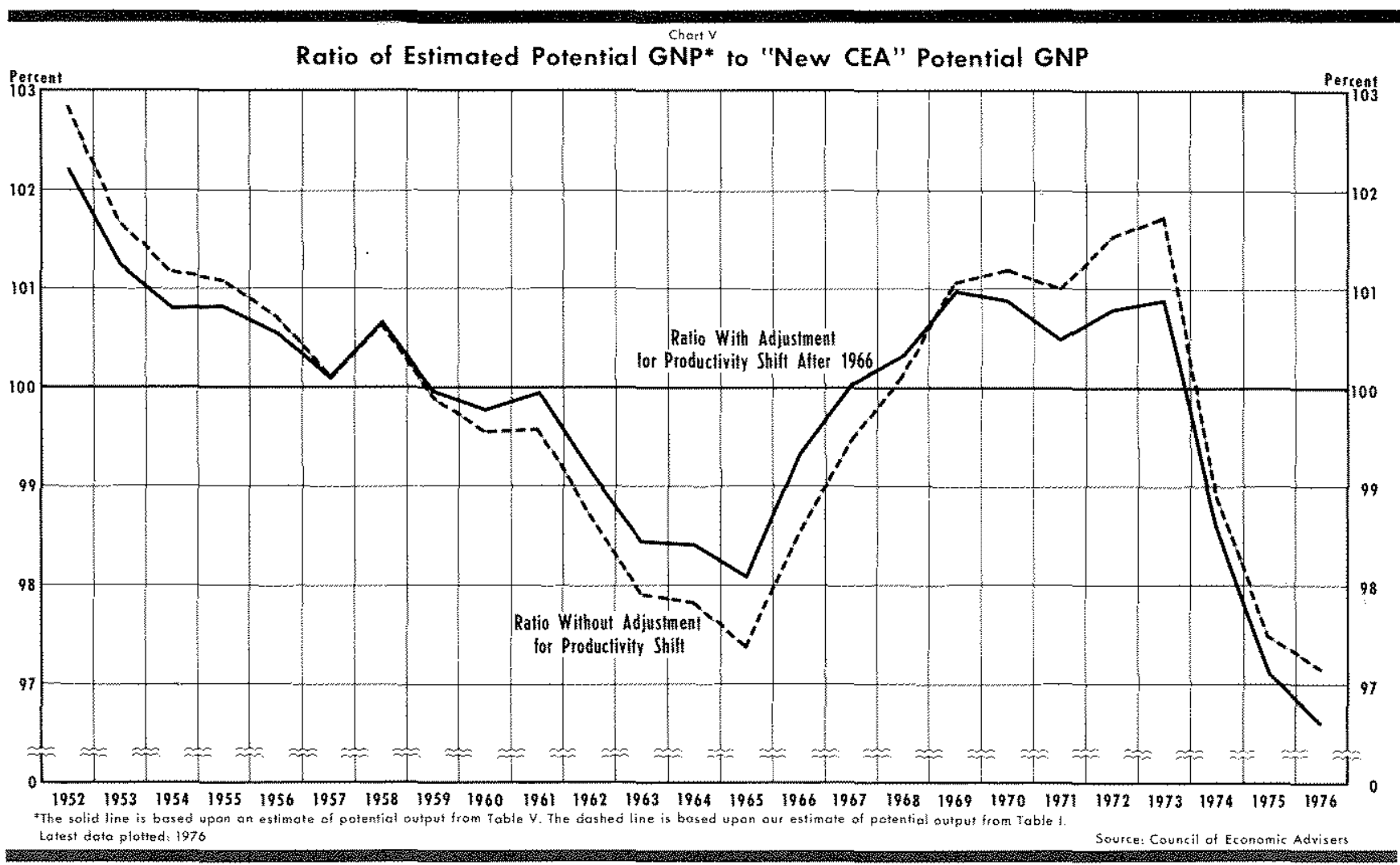

ments reduced potential output by an additional $\$ 30$ billion by $1976 .^{40}$ When this effect is subtracted from the new CEA estimate for 1976, the result is within one percent of our estimate of potential output. ${ }^{41}$

Our estimate of potential output suggests that in 1975 , the economy failed to produce about 7 percent

40"The $\$ 30$ billion reduction is a "conservative" estimate. Clark, "A New Measure of Potential Output," shows a 4.2 percent reduction in productivity in the private business sector which implies potential otitput measures for 1975 and 1976 of $\$ 1,273.7$ billion and $\$ 1,318.9$ billion, respectively. These estimates are even closer to our estimates derived from the Table I equation and given in Table VI.

41A regression of the relative price of energy on the time trend variables used by Clark, "A New Measure of Potential Output," shows why the estimates agree so well in recent years. The coefficients, with $t$ statistics in parentheses, for the quarterly time variables ate: $.0034(20.7)$ for a time trend for 1948 through $1975 ; .0036(5.6)$ for a time trend begiming in the first quarter of 1967; and $4823(23.0)$ for a shift variable which takes values of $.25, .5, .75$ from the first through the third quarter of 1974 , and one after that. The adjusted $R^{2}$ of this equation is .92 and the standard error is 3.5 percent. The first trend reflects the historical decline of 1.33 percent in the relative price of energy from 1948 to the end of the 1960 s. The shift term beginning in 1974 shows a rise of 48 percent in the relative price, 35.4 percent of which occurred from the fourth quarter of 1973 to the fourth quarter of 1974 . Such a shift in the relative price of energy shows how Clark's shift of potential private sector output down by 4.2 percent can be associated with the energy price. The coefficient of Clark's shift variable (.4823) in the energy price regression times the energy price coefficient in Table I (.1363) yields a permanent decline in potential ontput of 6.6 percent, about 50 percent larger than Clark's 4.2 percent. of its potential output due to the recession. In contrast the old and new CEA estimates suggest that the gap was about 13 percent and 10 percent, respectively. More importantly, the gap fell to 4.5 percent of potential output in 1976 while the CEA estimates indicate it only fell to 11 or 7 percent of potential output. On the basis of the old CEA series, the worst loss of potential output, prior to the 1973.75 recession, occurred in 1958 when the gap was about 6.5 percent of potential. Thus, both CEA estimates imply the economy performed very poorly relative to potential output in 1976. In contrast, a 4.5 percent shortfall of actual from potential output is about the same as the performance indicated by our historical series for $1960-61$ or 1971.

The gain in output to be achieved by moving to a fully-employed econony is substantially smaller than

Table vI

Three Measures of Potential Oufput (Bitlions of 1972 Dollars)

\begin{tabular}{|c|c|c|c|}
\hline OIdCEA & New CEA & $\begin{array}{l}\text { Production functon } \\
\text { fToble } 1\end{array}$ & Actual GNP \\
\hline 126 & $\$ 1228$ & $\$ 1249,2$ & 112350 \\
\hline 1 & 1271 & 1257.8 & 12140 \\
\hline & 13169 & 1283,8 & 1191.7 \\
\hline & 1363.6 & 13246 & 1264 \\
\hline
\end{tabular}


either the old or the new CEA measures indicate. Attempts to expand demand and production to such unattainable levels in the near term would consequently accelerate inflation. The period of time over which output may grow at a given rate faster than the growth rate of potential output is correspondingly smaller. The rate of growth of potential output will constrain actual output growth much earlier than the old measure suggests. Also, at the output rate achieved at full employment, Federal tax receipts and budget surpluses will be smaller than the higher measures of potential indicate. Thus, a goal of a balanced budget at full employment will require more effort than either of the CEA estimates indicate.

\section{CONCLUSIONS}

Since 1962 estimates of potential output have become popular and important sources of information for policy formulation. The early estimates, and until recently the official estimates, focused upon labor resources only. New estimates by the CEA have attempted, to some extent, to account explicitly for the importance of capital resources and a production function. The CEA has also suggested that tiergy developments are an important factor affecting the productivity of fully-employed resources.

Using a production function which accounts explicitly for capital and energy resources, an alternative measure of potential output has been developed. The production function estimates support the argu- ment that the new energy regime imposed in 1974 permanently reduced potential output by about four percent. The production function estimates show that failure to account for energy prior to 1973 is not critical, but that serious inconsistencies arise when the sample period is extended to include recent years.

Until 1973 the historical series for potential output developed here tends to conform more to the old CEA series than the new series. After 1973, however, the new CEA estimates adjusted for the magnitude of their suggested decline in productivity are very close to our estimates. "Thus, while our estimates cast some doubt on the historical accuracy of the new CEA estimates, they support the CEA's suggestion that energy price developments after 1973 reduced potential output.

The implications of the new CEA estimates and those presented here are of great significance for the full-employment and growth prospects of the economy. Attempts to achieve an unattainable potential output rate through stimulative policy will not only fail, but will add to inflationary pressures. Also, there is little prospect for an extended period of growth at rates higher than the rate of growth of potential output (about 3.5 percent per year). The gap between potential and actual output will tend to close within two years, even with the moderate growth of actual output achieved in 1976. Finally, at full employment, existing tax and spending policies will result in a much larger budget deficit than higher measures of potential output indicate.

\section{APPENDIX I}

\section{An Analysis of the Eckstein-Heien Model for Determining Potential Output ${ }^{1}$}

In a recent study for the Joint Economic Committee, Eckstein and Heien (E-H) have estimated an annual

1Albert J. Eckstein and Dale M. Heien, "Estimating Potential Output for the U.S. Economy in a Model Framework." Achieving the Goals of the Employment Act of 1946 - Thirtieth Annitertsary Review, U.S. Congress, Joint Economic Committee, 94th Cong., 2nd sess., December 3, 1976, pes. $1-25$. model which they use to construct an alternative to the official CEA potential output series. Since their analysis purports to introduce the impact of energy price changes on potential outpat, and since the conclusions of their analysis are remarkably different from those rem ported here, this appendix attempts to analyze the reasons for the different conclusions. 
The first difference involves the choice of data series. E-H choose to study the private nonfarm sector of the economy. This differs from the private business sector as defined in the text, in that the E-H measure excludes the farm sector of the economy, and includes the imputed output to owner-occupied housing and output originating in households and non-proft instifutions. They also choose to use raw materials as the third factor of production in their estimated production function, in contrast to the energy input concept employed above. In practice this difference should not be too important, since 88 percent of the weight in their Laspeyres index of raw materials comes from the crude oil, refined petroleum products, natural gas and coal components of their index. The wholesale price index of energy used above measures just these components plus electrical power, so the correlation of the two input measures should be very high.

E-H estimate a three factor Cobbwonglas production function on annual data from 1950-74. The estimated output elasticities in their function can be compared with those implied by the production function which is re ported above. All three estimated elasticities are essentially identical in both studies. In addition, the estimated coefficient on the time variable is almost exactly the same in both equations. The differences in the conclusions of the two studies, therefore, cannot be attributed to differences in the underlying production function, the central relationship in both analyses.

E-H present a 12 equation model, while the analysis above explicitly involves only one equation. For the purposes of constructing potential output, the elaboration in their 12 equations is somewhat misleading. They use the assumption that four percent unemployment is the appropriate rate of labor force utilization at which to construct potential output. With this assumption, their model can be characterized by three distinct blocks: 1) an employment block consisting of the labor force participation equations and the various identities defining em* ployment, labor force and unemployment, 2) a wagem price block consisting of the equations for the wage rate in the private nonfarm economy and the price of output in the private nonfarm economy, and 3) an ontput block consisting of the production function, a derived demand equation for raw materials, and an equation for the average hours per worker.

Under the assumed "full-employment" conditions, the employment block is completely independent of the rest of the model. The size of the male labor force is expressed solely as a function of exogenous variables, so it is also an exogenous variable for purposes of the model. The female labor force is a function of exogenous vari ables, other variables within the employment block of the model, and lagged variables from other blocks of the model. The various identities in this block relate variables defined within the block to exogenous variables. Therefore, it is possible to solve this subset of their equation system for the total private nonfarm employm ment as a function of only exogenous variables. Private nonfarm employment can affect variables in both the wage-price block and the output block.
The wage-price block is affected by two exogenous variables, the price of raw materials and the full-employment unemployment rate. It is also affected by the employment block and the output block, since these parts of the model determine employment and output which affect unit labor costs. Unit labor costs are specified as an important infuence in the detemination of private nonfarm wages.

The output block is affected by the exogenous capital stock and exogenous capacity utilization rate. It is affected by the employment block through employment in the private nonfarm sector which enters into the aggregate production function. Furthermore, the only link between the wage-price block and the output block is through the relationship for the average number of hours per worker, which depends on the real wage rate. This relationship is not particularly strong, since the elasticity of the average number of hours per worker with respect to the real wage rate is only 2 , but it explains why E.H obtain a positive relationship between raw materials prices and potential output.

In the $\mathrm{E} \cdot \mathrm{H}$ model, an increase in raw materials price directly affects the price of output in the nonfarm sector. A higher price level in turn causes higher wages, but the increase is less than proportional, so the real wage rate falls in response to the increase in raw materials prices. Real wages have a negative impact on the average number of hours per worker, so hours per worker rise in response to the increase in raw materials prices. But total private sector employment in the model is exogenous at potential output as discussed above, so total manhours rise in response to the increase in raw materials prices. The net effect is an elasticity of real output with respect to raw materials prices in the $\mathrm{E} \cdot \mathrm{H}$ model of .02 . The small magnitude of this elasticity illustrates the weakness of the interrelationship of the price-wage equations of the model with the output equation through the average hours equation.

If E-H had assumed, as do the authors of other studies of potential output, a fixed number of hours per person at full employment, then the link between the wageprice block and output block in their model would be broken. Their potential output model would then consist only of two equations; the production function and the demand for raw materials equation, supplemented by exogenous assumptions on the magnitade of manhours supplied at potential ontput. Under these circumstances their analysis would imply that there is no effect of changes in raw materials prices on potential output. In practice, their analysis effectively implies such a conclusion since the price elasticity reported above is so close to zero.

The two equation model which is so closely approximated by the E-H model is exactly the two equation model which is implicit in the analysis presented above. The aggregate production function, with the relative price of energy as one of the right hand side variables, is derived by substituting the demand equation for energy under the assumption that the real price of energy 
inputs is exogenous. Recall that the estimates of the production function parameters are essentially the same for the two studies. Therefore, the difference in the results obtained must be attributable to differences in the explicit or implicit demand functions for energy inputs.

The problem with the $\mathrm{E}-\mathrm{H}$ model is that the demand functions for both labor and raw material inputs are misspecified. Such demand functions normally would be expected to be consistent with the first-order conditions for cost minimization and/or profit maximization. In the case of the Cobb-Douglas production function, this implies that the input demand functions must be log-linear. Yet both the demand function for raw materials and the demand function for labor services in the E-H stady are specified as linear functions. This probably accomnts for the insignificance of the estimated coefficient of the relative price term in the raw material demand equation which $\mathrm{E}-\mathrm{H}$ report in the text, but not in the equations of the model.
The approach used in this study implicitly assumes that both the output elasticity and the price elasticity of the demand for energy are one, and that the functional form of this equation is log-linear. If this were not the case, then the output elasticities derived from the production function parameter estimates should be biased. Three pieces of evidence suggest that this is not the case. First, the estimated output elasticity of labor services conform quite closely to the share of labor in total income as it should under the constant-returns-to-scale restriction. Second, the estimated output elasticity of energy inputs conforms almost exactly with the estimates from crossusection time series data of several countries, including the United States obtained by Griffin and Gregory. Third, as mentioned above, the estimated output elasticity of energy (as well as of other resources) obtained in this study are almost identical to those obtained by $\mathrm{E}-\mathrm{H}$ even though they used a measure of the quantity of raw materials input in estimating the production function directly.

\section{APPENDIX II}

Equation (2) constrains both the output and price elasticities of energy demand to unity. Consider the unconstrained hypothesis for the energy demand curve:

$$
\ln E=\delta_{0}+\delta_{1} \ln Y-\delta_{2} \ln \left(\mathrm{P}_{\mathrm{E}} / \mathrm{P}_{\mathrm{B}}\right)+\epsilon
$$

If this is substituted in the Cobb-Douglas production function:

$$
\ln \mathrm{Y}=\mathrm{a}+\alpha \ln \mathrm{L}+\beta \ln \mathrm{K}+\gamma \ln \mathrm{E}+\mathrm{u}
$$

where $\alpha+\beta+\gamma=1$, the result is:

$$
\begin{aligned}
& {[\ln \mathrm{X}-\ln \mathrm{K}]=\beta_{1}+\beta_{2}[\ln \mathrm{L}-\ln \mathrm{K}]} \\
& +\beta_{3} \ln \left(\mathrm{P}_{4} \mathrm{P}_{1}\right)+\beta_{4} \ln \mathrm{K}+\frac{\gamma \epsilon+\mathrm{u}}{1-\delta_{1} \gamma} \\
& \text { wheze } \beta_{1}=\left(\frac{a+\delta_{0} \gamma}{1-\delta_{1} \gamma}\right) \quad \beta_{2}=\left(\frac{\alpha}{1-\delta_{1} \gamma}\right) \\
& \beta_{3}=\left(\frac{-\gamma \delta_{2}}{1-\delta_{1} \gamma}\right) \quad \beta_{4}=\left(\frac{-1+\alpha+\beta+\delta_{1} \gamma}{1-\delta_{1} \gamma}\right)
\end{aligned}
$$

Therefore, if the output elasticity of energy demand, $\delta_{1}$, were not unity, the specification which has been estimated would have an omitted variable, in $\mathrm{K}$, which would be correlated with at least one of the included regressors, (ln $\mathrm{L}-\mathrm{ln} \mathrm{K}$ ), so all of the estimated regression coefficients ( $\hat{\beta}^{\prime}$ 's) would be biased.

If the price elasticity of energy demand, $\delta_{2}$, is not unity, then the estimated regression coefficients ( $\hat{\beta}$ 's) are not biased, but the output elasticities which we have derived from the regression coefficients are biased. Our estimates of the output elasticities for labor and energy are $\alpha^{*}=\hat{\beta}_{2} /\left(1-\hat{\beta}_{3}\right)$ and $\gamma^{*}=\hat{\beta}_{3} /\left(1-\hat{\beta}_{3}\right)$, respectively. The unbiased estimates of these output elasticities are

$$
\hat{\gamma}=\gamma^{*}\left[\frac{1}{1+\left(\gamma^{*}-1\right)\left(1-\delta_{2}\right)}\right] \text { and } \hat{\alpha}=\theta^{*}\left[\frac{1}{1+\gamma^{*}\left(\frac{1-\delta_{3}}{\delta_{2}}\right)}\right]
$$

Consequently, if $\delta_{2}<1$, our estimate of the output elasticity of energy is biased downward and our estimate of the output elasticity of labor is biased upward. The consistency of our estimates of the output elasticities with estimates from other sources and the consistency of the output elasticity with the labor share data, suggests that biases from these sources are not substantial. Even if the output elasticities were biased because the price elasticity of energy demand was less than unity, the biases would not affect our potential output computations, since these are based on the unbiased estimated regression coefficients ( $\left.\hat{\beta}^{\prime} s\right)$. 


\section{APPENDIX III}

A quarterly series for potential GNP can be constructed using the same method and data when some additional assumptions are made concerning the data. The principal data problems involve quarterly estimates of the capital stock and potential employment or manhours.

Quarterly data on the stock of capital are found by prorating the annual year-end changes in the net stock of fixed nonresidential equipment and strictures over quarters using quarterly rates of investment in nonresidential fixed investment as the weights. Clark's annual data on the potential labor force are assumed to be for the second quarter of each year and a linear interpolation is used for other quarters. To find potential manhours, a quarterly estimate of hours per worker is obtained such as that contained in Table IV. The quarterly potential hours per worker is found by using Clark's full-employment unemployment rate for the respective years in the equation

$$
\begin{aligned}
& \ln \mathrm{IPW}=.8120 \ldots .0033 \mathrm{U}-.0010 \mathrm{t} \\
& \overline{\mathrm{R}}^{2}=.97 \\
& \text { S.E. }=.0062
\end{aligned}
$$

which is estimated for the period from the second quarter of 1948 through 1975.

The quarterly production function comparable to the annual estimate in Table I, (II/1948-IV/1975) is

$$
\begin{aligned}
& \ln \mathrm{Y}=1.5974+.7192 \ln \mathrm{L}+.2808 \ln \mathrm{K} \\
& \text { (14,20) (20.85) } \\
& -.1164 \ln P+.0045 t \\
& \begin{array}{ll}
(-5.64) \quad(15.00) & 0
\end{array} \\
& \begin{array}{ll}
\overline{\mathbf{R}}^{2}=.98 & \text { D.W. }=1.90
\end{array} \\
& \text { S.E. }=.008 \\
& \hat{\mathrm{p}}=.80
\end{aligned}
$$

The estimated coefficients are essentially the same as for the equation in Table 1 . The estimated output elasticities and trend growth term are (standard errors in parentheses )

$$
\begin{array}{r}
\hat{\alpha}=04.4 \%(3.08 \%), \hat{\beta}=25.2 \%(3.08 \%), \\
\hat{\gamma}=10.4 \%(1.85 \%), \hat{\mathrm{r}}=.4 \%(.03 \%) .
\end{array}
$$

